\title{
Tracing charge transfer in argon dimers by XUV-pump IR-probe experiments at FLASH
}

Cite as: J. Chem. Phys. 151, 084314 (2019); https://doi.org/10.1063/1.5116234

Submitted: 23 June 2019 . Accepted: 08 August 2019 . Published Online: 30 August 2019

Georg Schmid (D), Kirsten Schnorr, Sven Augustin, Severin Meister, Hannes Lindenblatt (D), Florian Trost (D), Yifan Liu, Tsveta Miteva (D), Mathieu Gisselbrecht, Stefan Düsterer, Harald Redlin, Rolf Treusch (D), Kirill Gokhberg (D), Alexander I. Kuleff (D), Lorenz S. Cederbaum (D), Claus Dieter Schröter, Thomas Pfeifer, and Robert Moshammer

\section{ARTICLES YOU MAY BE INTERESTED IN}

High harmonic generation spectroscopy via orbital angular momentum

The Journal of Chemical Physics 151, 084308 (2019); https://doi.org/10.1063/1.5115152

Solid state synthesis of CdS quantum dots through laser direct writing

AIP Conference Proceedings 2145, 020016 (2019); https://doi.org/10.1063/1.5123577

Production of ultracold ${ }^{85} \mathrm{Rb}^{133} \mathrm{Cs}$ molecules in the lowest ground state via the $\mathrm{B}^{1} \Pi_{1}$ shortrange state

The Journal of Chemical Physics 151, 084303 (2019); https://doi.org/10.1063/1.5108637

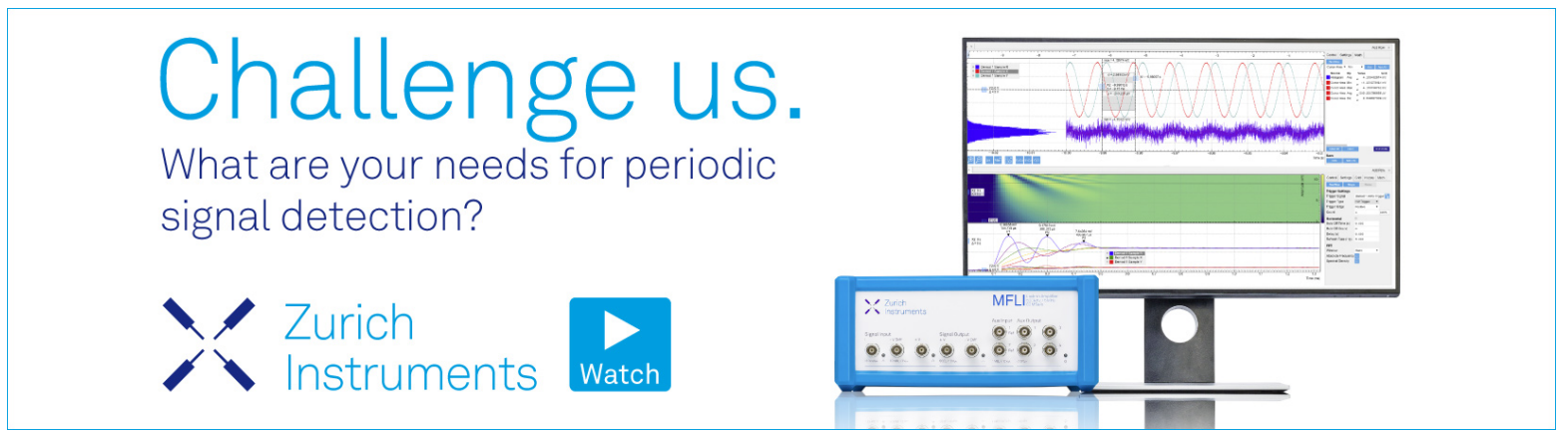




\title{
Tracing charge transfer in argon dimers by XUV-pump IR-probe experiments at FLASH
}

\author{
Cite as: J. Chem. Phys. 151, 084314 (2019); doi: 10.1063/1.5116234 \\ Submitted: 23 June 2019 - Accepted: 8 August 2019 • \\ Published Online: 30 August 2019
}

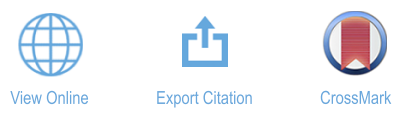

\section{Georg Schmid, , (D) Kirsten Schnorr, ${ }^{1, b)}$ Sven Augustin, ${ }^{1, b)}$ Severin Meister, ${ }^{1}$ Hannes Lindenblatt, \\ Florian Trost, ${ }^{1}$ (D) Yifan Liu, ${ }^{7}$ Tsveta Miteva, ${ }^{2,3}$ (D) Mathieu Gisselbrecht, ${ }^{4}$ Stefan Düsterer, ${ }^{5}$ Harald Redlin, \\ Rolf Treusch, ${ }^{5}$ (D) Kirill Gokhberg, ${ }^{2}$ (D) Alexander I. Kuleff, ${ }^{2}$ (D) Lorenz S. Cederbaum, ${ }^{2}$ (D) Claus Dieter Schröter, \\ Thomas Pfeifer, and Robert Moshammer ${ }^{1, c)}$}

\begin{abstract}
AFFILIATIONS
${ }^{1}$ Max-Planck-Institut für Kernphysik, Saupfercheckweg 1, 69117 Heidelberg, Germany

${ }^{2}$ Theoretische Chemie, Physikalisch-Chemisches Institut, Universität Heidelberg, Im Neuenheimer Feld 229,

69120 Heidelberg, Germany

${ }^{3}$ Sorbonne Université, CNRS, Laboratoire de Chimie Physique Matière et Rayonnement, F-75005 Paris, France

${ }^{4}$ Department of Physics, Lund University, PO Box 118, SE-22100 Lund, Sweden

${ }^{5}$ Deutsches Elektronen-Synchrotron, Notkestraße 85, 22607 Hamburg, Germany
\end{abstract}

a) Electronic mail: Georg.Schmid@mpi-hd.mpg.de

b) Current address: Paul Scherrer Institut, 5232 Villigen PSI, Switzerland.

${ }^{c}$ Electronic mail: Robert.Moshammer@mpi-hd.mpg.de

\begin{abstract}
Charge transfer (CT) at avoided crossings of excited ionized states of argon dimers is observed using a two-color pump-probe experiment at the free-electron laser in Hamburg (FLASH). The process is initiated by the absorption of three 27-eV-photons from the pump pulse, which leads to the population of $\mathrm{Ar}^{2+*}-\mathrm{Ar}$ states. Due to nonadiabatic coupling between these one-site doubly ionized states and two-site doubly ionized states of the type $\mathrm{Ar}^{+*}-\mathrm{Ar}^{+}$, CT can take place leading to the population of the latter states. The onset of this process is probed by a delayed infrared $(800 \mathrm{~nm})$ laser pulse. The latter ionizes the dimers populating repulsive $\mathrm{Ar}^{2+}-\mathrm{Ar}^{+}$states, which then undergo a Coulomb explosion. From the delay-dependent yields of the obtained $\mathrm{Ar}^{2+}$ and $\mathrm{Ar}^{+}$ions, the lifetime of the charge-transfer process is extracted. The obtained experimental value of $(531 \pm 136)$ fs agrees well with the theoretical value computed from Landau-Zener probabilities.
\end{abstract}

Published under license by AIP Publishing. https://doi.org/10.1063/1.5116234

\section{INTRODUCTION}

Understanding of molecular relaxation mechanisms behind charge migration and energy redistribution is of utmost relevance for a complete description of more general and thus more complex chemical processes which occur in chemical media. An isolated excited atom or molecule can relax via fluorescence or, if energetically allowed, by Auger decay (autoionization). If it is embedded in an environment, however, new interatomic or intermolecular relaxation pathways open up. These nonlocal relaxation processes involve energy transfer and/or charge exchange between the neighboring constituents.
In interatomic or intermolecular Coulombic decay (ICD), a relaxation mechanism predicted by Cederbaum et al. ${ }^{1}$ in 1997, an excited atom or molecule can relax by transferring its excess energy to a neighbor, which consequently becomes ionized. It was shown that ICD and related processes ${ }^{2}$ are omnipresent in weakly bound systems like dimers, ${ }^{3,4}$ clusters, ${ }^{5,6}$ endohedral fullerenes, ${ }^{7}$ and pure water $^{8,9}$ as well as in aqueous solutions. ${ }^{1}$

In argon dimers, ICD has been observed in numerous studies. Morishita et al. ${ }^{11}$ reported about experimental evidence of ICD in $\mathrm{Ar}_{2}$ by inner-valence ionization and subsequent intra-atomic Auger decay, thereby exciting ICD-active dimer states. Their work, as well as others, could undoubtedly demonstrate that ICD represents an 
important contribution to the relaxation of excited $\mathrm{Ar}_{2}{ }^{12-19}$ A resonant process of energy-transfer in $\mathrm{Ar}_{2}$, which happens below the energy threshold for ICD, has been reported by Mizuno et al. ${ }^{2}$ Therefore, a $3 s^{-1}$ hole created by photoionization is filled by a $3 p$ electron at the same site while the released energy is transferred to the neutral neighbor, which, in turn, becomes electronically excited, but not ionized like in ICD.

Besides mechanisms that involve only transfer of energy, excited $\mathrm{Ar}_{2}$ may also relax via pathways which in addition comprise charge transfer (CT) from one site to its neighbor. Electrontransfer mediated decay (ETMD) ${ }^{21}$ was observed by Sakai et al. ${ }^{22}$ in one-site triply ionized dimers with an inner-valence $3 s^{-1}$ vacancy $\left[\operatorname{Ar}^{3+}\left(3 s^{-1} 3 p^{-2}\right)-\operatorname{Ar}\right]$. In ETMD, an electron from the neutral $\mathrm{Ar}$ atom is transferred to the ion while another electron from the formerly neutral Ar atom is emitted into the continuum. The resulting $\mathrm{Ar}^{2+}-\mathrm{Ar}^{2+}$ dimer undergoes a Coulomb explosion. In radiative charge transfer (RCT), ${ }^{23}$ the transfer of an electron is accompanied by the emission of a photon. Saito et al. ${ }^{24}$ found evidence of RCT after excitation of states with the $\operatorname{Ar}^{2+}\left(3 p^{-2}\right)-\operatorname{Ar}$ configuration, which decay to $\mathrm{Ar}^{+}-\mathrm{Ar}^{+}$by emitting a photon.

Charge transfer (CT) can also take place at avoided crossings of electronic states. ${ }^{25}$ Different from RCT, however, the charge transfer is mediated by nonadiabatic couplings between the states and no photon is emitted. So far, this type of charge transfer has not been largely investigated in $\mathrm{Ar}_{2}$. It is discussed by Stoychev et al. ${ }^{18}$ and was observed in argon trimers. ${ }^{26}$

In this paper, we report a time-resolved study of charge transfer at avoided crossings of excited states in ionized $\mathrm{Ar}_{2}$. In order to populate CT-active states, we take advantage of the unique high photon intensities of free-electron laser $(\mathrm{FEL})^{27}$ radiation, which allows the absorption of multiple extreme-ultraviolet (XUV) photons within a single FEL pulse. In this way, specific dimer states can be excited via sequential ionization and excitation of electrons.

The sequential absorption of three 27-eV-photons leads to the population of the excited dicationic states of $\mathrm{Ar}^{2+}-\mathrm{Ar}$ character. These states of the dimer originate from the same atomic multiple and primarily comprise $\mathrm{Ar}^{2+}\left(3 s^{-1} 3 p^{-11} P\right)-\mathrm{Ar}$ and $\operatorname{Ar}^{2+}\left(3 p^{-3}\left({ }^{2} D\right) 3 d^{1} P\right)-\operatorname{Ar}$ configurations, which contribute to an equal degree. ${ }^{18}$ In the following, we will refer to these states as $\operatorname{Ar}^{2+}\left(3 s^{-1} 3 p^{-1}\right)-\mathrm{Ar}$ for brevity. These states are located about $61 \mathrm{eV}$ above the $\mathrm{Ar}_{2}$ ground state, i.e., in a regime where ICD is energetically not allowed (cf. Fig. 1). It has a bound potential energy curve (PEC) and is crossed by several repulsive states of $\operatorname{Ar}^{+}\left(3 p^{-2} n l\right)$ $-\operatorname{Ar}^{+}\left(3 p^{-1}\right)$ character. At the crossings, nonadiabatic couplings can lead to transitions to the repulsive PECs, ${ }^{18}$

$$
\operatorname{Ar}^{2+}\left(3 s^{-1} 3 p^{-1}\right)-\operatorname{Ar} \stackrel{\mathrm{CT}}{\longrightarrow} \operatorname{Ar}^{+}\left(3 p^{-2} n l\right)-\operatorname{Ar}^{+}\left(3 p^{-1}\right) .
$$

As the neutral Ar becomes singly charged and the $\mathrm{Ar}^{2+}$ ion is partially neutralized in the transition, the underlying process is a charge transfer.

In order to trace this charge transfer in time, we employ XUVpump IR-probe spectroscopy. Following the ionization with intense FEL radiation, pulses of a synchronized IR laser are used to probe the population of the states after charge transfer [cf. Eq. (1)] by ionizing the excited $n l$ electrons, finally reaching repulsive triply ionized states $\left[\operatorname{Ar}^{2+}\left(3 p^{-2}\right)-\mathrm{Ar}^{+}\left(3 p^{-1}\right)\right]$. The delay-dependent yields of $\mathrm{Ar}^{2+}$ and $\mathrm{Ar}^{+}$ions from Coulomb explosions carry information about the

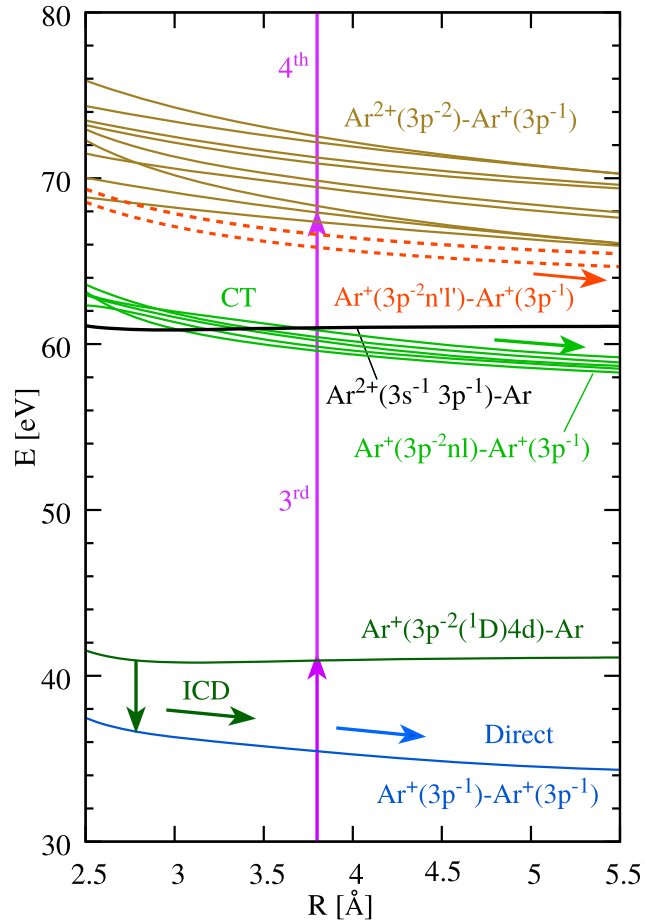

FIG. 1. Potential energy curves of the argon dimer relevant for the presen experiment in the interval $30-80 \mathrm{eV}$. The potential energy $E$ is given with respect to the $\mathrm{Ar}-\mathrm{Ar}$ ground state. The $\mathrm{Ar}^{2+}\left(3 s^{-1} 3 p^{-1}\right)-\mathrm{Ar}$ (black curve) and $\operatorname{Ar}^{+}\left(3 p^{-2} n l\right)-\operatorname{Ar}^{+}\left(3 p^{-1}\right)$ states (light-green curves) are calculated in this paper. The $\operatorname{Ar}^{+}\left(3 p^{-2} n^{\prime} l^{\prime}\right)-\operatorname{Ar}^{+}\left(3 p^{-1}\right)$ Rydberg states (orange dotted curves) were approximated as $\operatorname{Ar}^{+}\left(3 p^{-2}\left({ }^{1} D\right) 3 d^{2} P\right)-\operatorname{Ar}^{+}\left(3 p^{-1}\right)$ states ${ }^{18}$ which are asymptotically shifted to respective values taken from NIST. ${ }^{36}$ The remaining potential energy curves are taken from Stoychev et al. ${ }^{18}$ and Miteva et al. ${ }^{19}$ For simplicity, only one PEC of the manifold of $\operatorname{Ar}^{+}\left(3 p^{-1}\right)-\operatorname{Ar}^{+}\left(3 p^{-1}\right)$ states is depicted (blue curve). The purple vertical arrows indicate transitions with photons of $\hbar \omega=27 \mathrm{eV}$ at the equilibrium internuclear distance.

lifetime of the charge-transfer process. The experiment is compared to calculations based on Landau-Zener (LZ) probabilities.

In Sec. II, the experimental and theoretical methods are presented. In Sec. III, we identify the relaxation channels following sequential XUV photoabsorption and then focus on the determination and calculation of the charge-transfer lifetime. The conclusions are given in Sec. IV.

\section{METHODS}

\section{A. Experiment}

The experiment was carried out at beamline BL2 at the freeelectron laser FLASH. ${ }^{28}$ FEL pulses of $(27.0 \pm 0.5) \mathrm{eV}$ (FWHM) photon energy and pulse durations of approximately $50 \mathrm{fs}$ (FWHM) were spatially and temporally overlapped with near-infrared (IR) pulses from a synchronized Ti:Sa laser ${ }^{29}$ with a $10 \mathrm{~Hz}$ pulse repetition rate. The FEL beam was focused down to a diameter of approximately $20 \mu \mathrm{m}$ by an ellipsoidal mirror, ${ }^{28}$ whereas the IR beam was focused by a lens. To collinearly overlap the two beams, the IR laser 
is deflected by $90^{\circ}$ with a holey mirror. A large IR focus of about $50 \mu \mathrm{m}$ ensures that the interaction region is uniformly probed.

The FEL pulse energy was $E_{\mathrm{FEL}}=10-20 \mu \mathrm{J}$, and the intensity is estimated to $I_{\mathrm{FEL}} \approx 10^{13}-10^{14} \mathrm{~W} / \mathrm{cm}^{2}$ and that of the IR laser to $I_{\mathrm{IR}} \approx 10^{14} \mathrm{~W} / \mathrm{cm}^{2}$. The IR laser polarization axis is perpendicular to the FEL polarization axis. The overall temporal resolution of the experiment is $(280 \pm 20)$ fs $(F W H M)$. It is determined by fitting an error function to the simultaneously measured XUV-IR delay-dependent yield of atomic $\mathrm{Ar}^{2+}$ ions. Two 27-eV-photons are sequentially absorbed to resonantly excite long-lived $\mathrm{Ar}^{+*}$ states just below the double ionization threshold. A delayed IR pulse efficiently probes these $\mathrm{Ar}^{+*}$ states to $\mathrm{Ar}^{2+}$ by ionizing the excited electron. This gives rise to a step-like yield of $\mathrm{Ar}^{2+}$ ions as a function of the XUV-IR delay. The rising slope of the step defines the temporal resolution. It is the convolution of the FEL and IR laser pulse durations and includes the temporal jitter between the FEL and the IR laser. ${ }^{29}$

Both beams are focused into a supersonic gas jet at the center of a reaction microscope. ${ }^{30}$ Argon dimers are produced by expanding pure argon gas through a $30 \mu \mathrm{m}$ diameter nozzle with an injection pressure of 2 bars. The ratio of dimers to monomers within the target jet was determined to be about 1:20.

Ions are guided onto a large-area (120 $\mathrm{mm}$ diameter) time- and position-sensitive detector by means of a homogeneous electric field $(55 \mathrm{~V} / \mathrm{cm})$. By measuring the time-of-flight and the impact position on the detector, the three-dimensional momentum of each ion is reconstructed. Momentum conservation is employed to select those ions resulting from the fragmentation of $\mathrm{Ar}_{2}$ that emerge from the same dimer and the corresponding kinetic energy release (KER) is determined.

\section{B. Theory}

The PECs of the doubly-ionized states of $\mathrm{Ar}_{2}$ were computed with the second-order Algebraic Diagrammatic Construction $[\mathrm{ADC}(2)]$ approach to the two-particle propagator ${ }^{31,32}$ using the cc-pVQZ basis set ${ }^{33}$ augmented with 5 sets of $s$, p, and d diffuse functions $^{34}$ (cf. Fig. 1). The Hartree-Fock orbital energies and twoelectron integrals needed for the ADC calculation were computed with the GAMESS-US package.

\section{RESULTS AND DISCUSSION}

\section{A. XUV excitation scheme}

In what follows, we disentangle the electronic relaxation processes in $\mathrm{Ar}_{2}$ following the sequential absorption of 27-eV-photons by analyzing their fingerprints in the coincident KER spectra of $\mathrm{Ar}^{+}$ and $\mathrm{Ar}^{2+}$ ions.

The potential energy curves of the states relevant for the discussion are presented in Fig. 1. Starting from the neutral Ar-Ar ground state, the absorption of one photon results in single ionization of the dimer,

$$
\mathrm{Ar}-\mathrm{Ar} \stackrel{1^{\text {st }} \mathrm{XUV}}{\longrightarrow} \operatorname{Ar}^{+}\left(3 p^{-1}\right)-\mathrm{Ar}
$$

Then, the absorption of a second photon can either happen at the neutral site or at the already ionized site. In the first case, repulsive two-site doubly ionized states are populated,

$$
\operatorname{Ar}^{+}\left(3 p^{-1}\right)-\operatorname{Ar} \stackrel{2^{\text {nd }} \mathrm{XUV}}{\longrightarrow} \operatorname{Ar}^{+}\left(3 p^{-1}\right)-\operatorname{Ar}^{+}\left(3 p^{-1}\right)
$$

This leads to a direct Coulomb explosion of the dimer at the equilibrium internuclear distance, $R_{\mathrm{eq}}=3.76 \AA^{37}$ (cf. Fig. 1). The $\mathrm{Ar}^{+}+\mathrm{Ar}^{+}$ions obtained from this direct channel are expected to have kinetic energies with a maximum around $3.8 \mathrm{eV}$, and therefore, they contribute to the lowest peak on the KER spectrum shown in Fig. 2.

If the second photon is absorbed at the already singly ionized site, a one-site singly ionized excited state is resonantly populated,

$$
\operatorname{Ar}^{+}\left(3 p^{-1}\right)-\operatorname{Ar} \stackrel{2^{\text {nd }} \mathrm{XUV}}{\longrightarrow} \operatorname{Ar}^{+}\left(3 p^{-2}\left({ }^{1} D\right) 4 d^{2} S\right)-\operatorname{Ar} .
$$

This state has enough energy to undergo ICD,

$$
\begin{gathered}
\operatorname{Ar}^{+}\left(3 p^{-2}\left({ }^{1} D\right) 4 d^{2} S\right)-\operatorname{Ar} \\
\downarrow \operatorname{ICD} \\
\operatorname{Ar}^{+}\left(3 p^{-1}\right)-\operatorname{Ar}^{+}\left(3 p^{-1}\right) .
\end{gathered}
$$

Due to the long ICD lifetime (1.4 ps at $R_{\mathrm{eq}}{ }^{17}$ ) compared to the vibrational period of this state, ICD competes with the vibrational motion. The former therefore occurs predominantly in the vicinity of the classical inner turning point, ${ }^{17,19}$ i.e., at $R \approx 2.7 \AA$ where the ICD lifetime is the shortest (cf. Fig. 1, dark-green PEC). Accordingly, the decay of this state gives rise to the peak at $5.3 \mathrm{eV}$ in the KER spectrum in Fig. 2.

The absorption of a third photon can happen on either site of the dimer. From the $\mathrm{Ar}^{+}\left(3 p^{-2} 4 d\right)-\operatorname{Ar}$ state [cf. Eq. (4)], if the photon is absorbed by the neutral site, Rydberg states just below the triple ionization threshold are populated (cf. Fig. 1, orange PECs),

$$
\operatorname{Ar}^{+}\left(3 p^{-2} 4 d\right)-\operatorname{Ar} \stackrel{3^{\text {rd }} \mathrm{XUV}}{\longrightarrow} \operatorname{Ar}^{+}\left(3 p^{-2} n^{\prime} l^{\prime}\right)-\operatorname{Ar}^{+}\left(3 p^{-1}\right) \text {. }
$$

Their PECs are repulsive, and the dimers with these states populated therefore fragment via so-called frustrated triple ionization (FTI) ${ }^{38-40}$ The KER during the fragmentation depends on the radius of the orbit of the Rydberg electron $R_{\text {Ryd }}$. If it is smaller than the

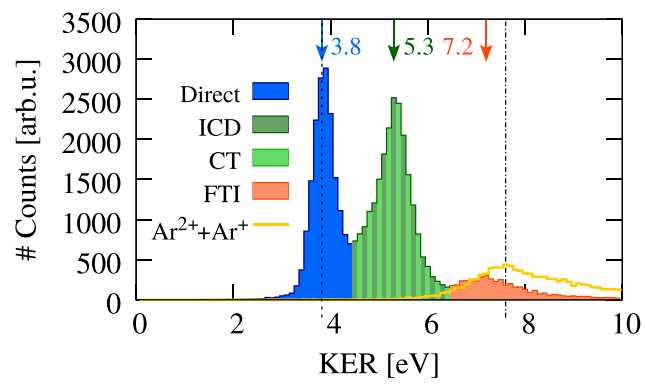

FIG. 2. Kinetic energy release (KER) of $\mathrm{Ar}^{+}+\mathrm{Ar}^{+}$ions measured in coincidence Contributions from different channels are color-coded. The KER of $\mathrm{Ar}^{2+}+\mathrm{Ar}^{+}$ions is superimposed (yellow curve). The vertical dashed and dashed-dotted lines mark the expected KER for fragmentation into $\mathrm{Ar}^{+}+\mathrm{Ar}^{+}$and $\mathrm{Ar}^{2+}+\mathrm{Ar}^{+}$at the equilibrium internuclear distance $R_{\text {eq }}$, respectively. The peaks designated with arrows are discussed in the text. 
internuclear separation $R, R_{\mathrm{Ryd}}<R$, the KER will be equal to that of two singly-ionized ions at the equilibrium interatomic distance, $\mathrm{KER} \approx 3.8 \mathrm{eV}$. If however, the orbit of the Rydberg electron extends beyond the internuclear separation, $R_{\mathrm{Ryd}}>R$, a KER close to that of an $\mathrm{Ar}^{2+}+\mathrm{Ar}^{+}$fragmentation will be observed. The KER spectrum of $\mathrm{Ar}^{2+}+\mathrm{Ar}^{+}$ions is measured in the experiment as well. Multiphoton absorption leads to the direct population of two-site triply charged states, $\operatorname{Ar}^{2+}\left(3 p^{-2}\right)-\operatorname{Ar}^{+}\left(3 p^{-1}\right)$ (cf. Fig. 1). These states are repulsive and their signature can be observed in the KER spectrum of $\mathrm{Ar}^{2+}$ $+\mathrm{Ar}^{+}$ions, which is also shown in Fig. 2. It exhibits a single peak at $7.5 \mathrm{eV}$. At the same time, the $\mathrm{Ar}^{+}+\mathrm{Ar}^{+} \mathrm{KER}$ spectrum in Fig. 2 shows a peak at $7.2 \mathrm{eV}$, which we therefore attribute to FTI of the $\operatorname{Ar}^{+}\left(3 p^{-2} n^{\prime} l^{\prime}\right)-\operatorname{Ar}^{+}\left(3 p^{-1}\right)$ states.

Alternatively, the third photon can be absorbed at the already ionized excited site populating the CT-active $\operatorname{Ar}^{2+}\left(3 s^{-1} 3 p^{-1}\right)-\mathrm{Ar}$ state (cf. Fig. 1, black curve),

$$
\operatorname{Ar}^{+}\left(3 p^{-2} 4 d\right)-\operatorname{Ar} \stackrel{3^{\text {rd }} \mathrm{XUV}}{\longrightarrow} \operatorname{Ar}^{2+}\left(3 s^{-1} 3 p^{-1}\right)-\operatorname{Ar}
$$

The $\operatorname{Ar}^{2+}\left(3 s^{-1} 3 p^{-1}\right)$ atomic state splits into four states in the dimer${ }^{1} \Sigma_{g}^{+},{ }^{1} \Sigma_{u}^{+},{ }^{1} \Pi_{g}$, and ${ }^{1} \Pi_{u}$. Already asymptotically, the identification of these states and the character of the states crossing them is a tedious task due to the high density of states in this region of the energy spectrum. We therefore restrict our analysis to the $\operatorname{Ar}^{2+}\left(3 s^{-1} 3 p^{-1}\right)$ $-\mathrm{Ar}^{1} \Sigma_{g}^{+}$state. With the aid of the NIST database, ${ }^{36}$ we analyzed the states below $\operatorname{Ar}^{2+}\left(3 s^{-1} 3 p^{-1}\right)-\mathrm{Ar}^{1} \Sigma_{g}^{+}$asymptotically. Thus, we identified the crossings between the left turning point of the respective PEC $(\approx 2.96 \AA)$ and the ground state equilibrium interatomic distance $(3.76 \AA) .{ }^{37}$ In our calculation, there are 5 such states with the $\operatorname{Ar}^{+}\left(3 p^{-2} n l\right)-\operatorname{Ar}^{+}\left(3 p^{-1}\right)$ configuration (cf. Fig. 1, light-green curves).

Assuming sequential instantaneous ionization and excitation processes, the CT-active state is populated at the ground-state equilibrium distance. Since the corresponding PEC is bound, the dimer starts shrinking and charge transfer occurs at the avoided crossings between $R=3.0-3.7 \AA$, i.e., at larger internuclear distances compared to ICD. However, since the $\operatorname{Ar}^{+}\left(3 p^{-2} n l\right)-\operatorname{Ar}^{+}\left(3 p^{-1}\right)$ PECs are steeper compared to the $\operatorname{Ar}^{+}\left(3 p^{-1}\right)-\operatorname{Ar}^{+}\left(3 p^{-1}\right)$ ones, charge transfer also contributes to the KER peak at $\approx 5.3 \mathrm{eV}$ (cf. Fig. 2)

\section{B. XUV-pump IR-probe scheme}

After having identified the excitation and relaxation channels in the static multiphoton study, in what follows, the time-resolved measurement of the CT process is discussed. The XUV-pump IRprobe scheme is illustrated in Fig. 3. The XUV-pump pulse populates the CT-active $\mathrm{Ar}^{2+}\left(3 s^{-1} 3 p^{-1}\right)-\mathrm{Ar}$ state. Assuming instantaneous excitation and ionization processes, it is populated at the ground-state equilibrium distance. Due to the bound character of this state, the wave packet starts propagating toward smaller internuclear distances thus reaching the avoided crossings with $\operatorname{Ar}^{+}\left(3 p^{-2} n l\right)$ $-\operatorname{Ar}^{+}\left(3 p^{-1}\right)$ states (cf. Fig. 3, light-green PECs), where charge transfer happens (cf. Fig. 3, orange-shaded area). The population of these states, and therefore the lifetime of the CT process, is probed by a delayed IR laser pulse, which removes the excited $n l$ electron reaching a triply ionized state (cf. Fig. 3, gray PEC),

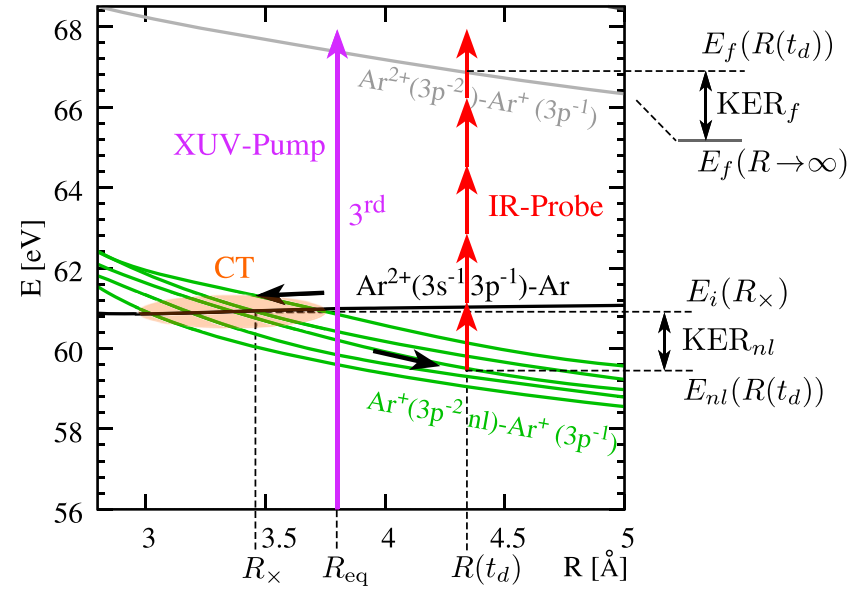

FIG. 3. Potential energy curves (PECs) of the argon dimer in the energy range 56-68.5 eV relevant for the experiment. The absorption of a third XUV photon (purple arrow) leads to the population of the $\mathrm{Ar}^{2+}\left(3 s^{-1} 3 p^{-1}\right)$-Ar state (black curve) at $R_{\text {eq }}$. Due to the bound character of the respective PEC, the wave packet starts to evolve to smaller distances. At the crossings (orange-shaded area) with $\operatorname{Ar}^{+}\left(3 p^{-2} n l\right)-\mathrm{Ar}^{+}\left(3 p^{-1}\right)$ states (light-green curves), charge transfer may happen. The IR pulse (red arrows) probes the population of the $\operatorname{Ar}^{+}\left(3 p^{-2} n l\right)-\operatorname{Ar}^{+}\left(3 p^{-1}\right)$ states by ionization to triply ionized $\mathrm{Ar}^{2+}\left(3 p^{-2}\right)-\mathrm{Ar}^{+}\left(3 p^{-1}\right)$ states (gray curve). For simplicity, only the lowest-lying PEC of the manifold of $\operatorname{Ar}^{2+}\left(3 p^{-2}\right)-\operatorname{Ar}^{+}\left(3 p^{-1}\right)$ states is depicted. Relevant potential energies and corresponding internuclear distances are indicated by horizontal and vertical dashed lines, respectively.

$$
\begin{aligned}
\operatorname{Ar}^{+}\left(3 p^{-2} n l\right) & -\operatorname{Ar}^{+}\left(3 p^{-1}\right) \\
\downarrow & \text { IR Probe } \\
\operatorname{Ar}^{2+}\left(3 p^{-2}\right)- & \operatorname{Ar}^{+}\left(3 p^{-1}\right) .
\end{aligned}
$$

From Fig. 3 and Eq. (8), one sees that the IR probe can only ionize to triply ionized states if the charge transfer has already happened. Thus, charge transfer can be followed in time by measuring the yields of $\mathrm{Ar}^{2+}+\mathrm{Ar}^{+}$and $\mathrm{Ar}^{+}+\mathrm{Ar}^{+}$ions as a function of the pumpprobe delay. As discussed in Sec. III A, the KER encodes information about the dimer fragmentation dynamics and thus allows selecting the $\mathrm{Ar}^{2+}$ and $\mathrm{Ar}^{+}$ions which are relevant to measure the CT lifetime.

Figure 4(a) shows the delay-dependent KER of Coulombexploded $\mathrm{Ar}^{2+}$ ions. Due to the $10 \mathrm{~Hz}$ repetition rate of the IR laser, the count rate in the $\mathrm{Ar}^{2+}+\mathrm{Ar}^{+}$coincidence channel is very low and thus noncoincident data have been included in the data analysis to improve statistics. However, having already identified the relaxation channels by their respective KER in the static study (cf. Sec. III A), where ions are recorded in coincidence, alleviates to process noncoincident pump-probe data. To distinguish $\mathrm{Ar}^{2+}$ ions originating from Coulomb explosions of dimers from those stemming from ionization events of monomers, a time-of-flight and position condition is used for the data shown in Figs. 4(a)-4(d).

First, the delay-dependent features of Fig. 4(a) are discussed. A KER trace starting from $\sim 7.5 \mathrm{eV}$ at delay zero and asymptotically reaching $\sim 5.3 \mathrm{eV}$ at $+4 \mathrm{ps}$ is observed. This delay-dependent KER is discussed by means of Fig. 3. As the initial $\operatorname{Ar}^{2+}\left(3 s^{-1} 3 p^{-1}\right)$ $-\mathrm{Ar}$ state is very flat in the region between $R_{\mathrm{eq}}$ and the internuclear distances at the crossings, the total KER of final $\mathrm{Ar}^{2+}+\mathrm{Ar}^{+}$ions is 

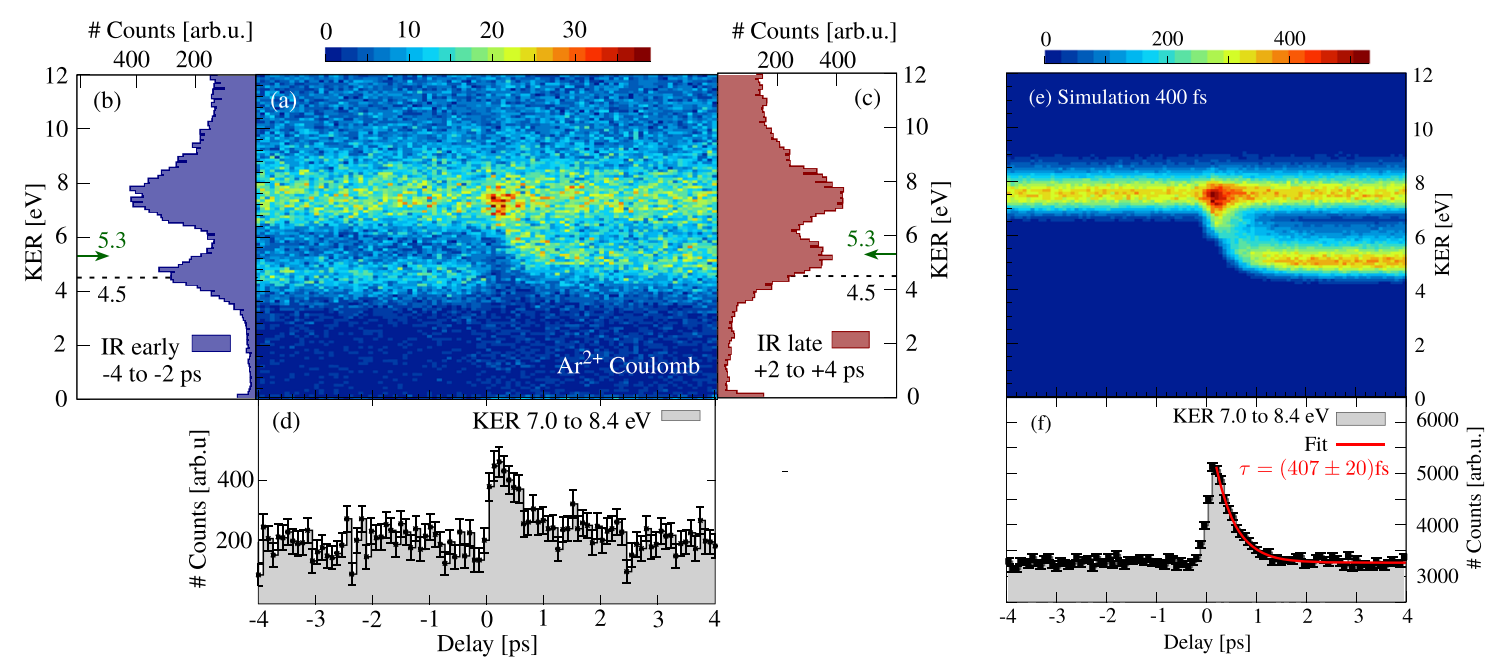

FIG. 4. (a) Delay-dependent KER spectrum of Coulomb-exploded $\mathrm{Ar}^{2+}$ ions. (b) Projection onto the KER axis for delays between -4 and -2 ps. (c) Same as (b), but for positive delays: from +2 to $+4 \mathrm{ps}$. (d) Projection onto the delay axis for KERs between 7.0 and $8.4 \mathrm{eV}$. (e) Theoretical delay-dependent KER spectrum of the A ${ }^{2+}+\mathrm{Ar}^{+}$ channel. A charge-transfer lifetime of $\tau=400 \mathrm{fs}$ was used as an input for the simulation. (f) Projection onto the delay axis for KERs between 7.0 and $8.4 \mathrm{eV}$. The red curve shows the result of an exponential fit.

in good approximation given by the $\mathrm{KER}_{n l}$ gained on the respective $\operatorname{Ar}^{+}\left(3 p^{-2} n l\right)-\operatorname{Ar}^{+}\left(3 p^{-1}\right)$ PEC and $\operatorname{KER}_{f}$ accumulated on the final $\operatorname{Ar}^{2+}\left(3 p^{-2}\right)-\operatorname{Ar}^{+}\left(3 p^{-1}\right)$ PEC,

$$
\begin{aligned}
\mathrm{KER} & \approx \mathrm{KER}_{n l}+\mathrm{KER}_{f} \\
& =E_{i}\left(R_{\times}\right)-E_{n l}\left(R\left(t_{d}\right)\right)+E_{f}\left(R\left(t_{d}\right)\right)-E_{f}(R \rightarrow \infty),
\end{aligned}
$$

where $E_{i}$ is the potential energy on the initial $\operatorname{Ar}^{2+}\left(3 s^{-1} 3 p^{-1}\right)-\mathrm{Ar}$ state, $E_{n l}$ is that of an intermediate $\operatorname{Ar}^{+}\left(3 p^{-2} n l\right)-\operatorname{Ar}^{+}\left(3 p^{-1}\right)$ state, and $E_{f}$ is that of the final $\mathrm{Ar}^{2+}\left(3 p^{-2}\right)-\operatorname{Ar}^{+}\left(3 p^{-1}\right)$ state. $R_{\times}, R\left(t_{d}\right)$, and $R$ $\rightarrow \infty$ are the internuclear distances at the crossing, at the instant $t_{d}$ of the IR probe, and in the asymptotic limit, respectively.

The measured asymptotic KER of $\sim 5.3 \mathrm{eV}$ [cf. Fig. 4(c)] matches that of the CT channel [cf. Fig. 2], and the delay-dependent KER in Fig. 4(a) behaves as expected from Eq. (9).

Contributions to the signal from probing the ICD channel [cf. Eq. (5)] are expected to be negligible. The IR-ionization probability of the excited $n l$ electron of the $\operatorname{Ar}^{+}\left(3 p^{-2} n l\right)-\operatorname{Ar}^{+}\left(3 p^{-1}\right)$ states is much higher compared to that of ionizing a $3 p$ electron from the lower-lying $\operatorname{Ar}^{+}\left(3 p^{-1}\right)-\operatorname{Ar}^{+}\left(3 p^{-1}\right)$ states, the final states after ICD.

The energy difference between the $\operatorname{Ar}^{+}\left(3 p^{-2} n l\right)-\operatorname{Ar}^{+}\left(3 p^{-1}\right)$ states and the final $\mathrm{Ar}^{2+}\left(3 p^{-2}\right)-\mathrm{Ar}^{+}\left(3 p^{-1}\right)$ state changes as a function of the internuclear distance $R$. This implies an $R$-dependent IR-ionization probability as different numbers of photons are required in the probe step depending on the internuclear distance $R\left(t_{d}\right)$ at the moment of the probe. As in the first approximation KER $\propto$ $1 / R$, the use of an explicit KER window circumvents an $R$-dependent IR-ionization probability as restricting the KER corresponds to restricting the internuclear distance $R\left(t_{d}\right)$ up to which the final states after charge transfer $\left[\operatorname{Ar}^{+}\left(3 p^{-2} n l\right)-\operatorname{Ar}^{+}\left(3 p^{-1}\right)\right]$ are probed.

Restricting the KER is also necessary for another reason. The population of the $\operatorname{Ar}^{+}\left(3 p^{-2} n l\right)-\operatorname{Ar}^{+}\left(3 p^{-1}\right)$ states consists of three contributions: the gain by charge transfer, the loss by the IR probe, and the loss by dissociation. Employing a KER window ensures that the interplay between these contributions is investigated within a fixed range of internuclear distances. This is a basic requirement for the applied method to extract the CT lifetime. ${ }^{20}$ For these reasons, and in accordance with the KERs measured in the static experiment (cf. Fig. 2), KER windows of 7.0-8.4 eV and 4.8-5.8 eV are applied to measure the yields of $\mathrm{Ar}^{2+}$ and $\mathrm{Ar}^{+}$ ions, respectively, which are used to determine the CT lifetime (cf. Sec. III D).

An increase in the yield of $\mathrm{Ar}^{2+}$ ions with KERs from 7.0 to $8.4 \mathrm{eV}$ for delays between 0 and +1 ps is visible in Fig. 4(a) and also in the corresponding projection onto the delay axis [cf. Fig. 4(d)]. The yield increases step-like at time zero and slowly drops toward positive delays. In Secs. III C and III D, it is shown that this drop is a measure of the CT lifetime.

Besides the delay-dependent features discussed so far, Fig. 4(a) shows delay-independent features. A constant KER contribution is present at $7.5 \mathrm{eV}$ [see also Figs. 4(b) and $4(\mathrm{c})$ ], which originates from ionization to two-site triply ionized states $\left[\operatorname{Ar}^{2+}\left(3 p^{-2}\right)-\operatorname{Ar}^{+}\left(3 p^{-1}\right)\right]$ (cf. Fig. 1) by absorption of multiple $27-\mathrm{eV}$-photons of the XUV pulse.

For negative delays (IR pulse early), a delay-independent contribution at $\mathrm{KER} \approx 4.5 \mathrm{eV}$ is observed [cf. Fig 4(b)], which vanishes for positive delays. This contribution is also present in the noncoincident data of Coulomb-exploded $\mathrm{Ar}^{2+}$ ions in the static XUV experiment (not shown), but not in the coincident $\mathrm{Ar}^{2+}+\mathrm{Ar}^{+}$data (cf. Fig. 2). Thus, the contribution stems from a fragmentation into $\mathrm{Ar}^{2+}+\mathrm{Ar}$, which is solely induced by XUV photoabsorption. Besides Rydberg states of the $\operatorname{Ar}^{+}\left(3 p^{-2} n^{\prime} l^{\prime}\right)-\operatorname{Ar}^{+}\left(3 p^{-1}\right)$ configuration [cf. Eq. (6)], Rydberg states of the $\operatorname{Ar}^{2+}\left(3 p^{-2}\right)-\operatorname{Ar}\left(3 p^{-1} n^{\prime \prime} l^{\prime \prime}\right)$ configuration can also be excited and the $4.5-\mathrm{eV}$-channel can be assigned to frustrated ionization: the Rydberg electron alters the shielding of the 
nuclear charges and the KER is close to that of two singly charged ions, $3.8 \mathrm{eV}$.

The absence of the KER $\approx 4.5 \mathrm{eV}$ contribution for positive delays (IR pulse late) supports this interpretation. The $\operatorname{Ar}^{2+}\left(3 p^{-2}\right)$ $-\operatorname{Ar}\left(3 p^{-1} n^{\prime \prime} l^{\prime \prime}\right)$ states are located just below the triple ionization threshold and for positive delays, the IR probe pulse ionizes the excited $n^{\prime \prime} l^{\prime \prime}$ electron.

\section{Classical simulation}

In order to extract the CT lifetime from the data in Figs. 4(a)4(d), the experiment is modeled by a classical simulation similar to that used in Refs. 4 and 41. Within this model, the nuclear motion is simulated as a motion of classical particles on potential energy curves according to Newton's classical equations of motion.

The simulation starts with the population of the $\mathrm{Ar}^{2+}\left(3 s^{-1} 3 p^{-2}\right)$ -Ar state (cf. Fig. 3, black PEC) by the XUV-pump pulse at time $t_{0}=0$. The subsequent oscillatory motion and dispersive broadening of the nuclear wave packet are not explicitly taken into account. They are rather included into the simulation by assuming a common lifetime $\tau>0$ after which the point-like classical particle is placed onto one of the repulsive $\operatorname{Ar}^{+}\left(3 p^{-2} n l\right)-\operatorname{Ar}^{+}\left(3 p^{-1}\right)$ PECs (cf. Fig. 3, green PECs) at the respective crossing. The probability for reaching a specific repulsive state is given by the Landau-Zener probabilities for each crossing (cf. Sec. III E). On the repulsive PEC, the particle propagates until the arrival of the probe pulse, which promotes the particle to a $2 / R$ Coulomb curve after a variable time $t_{\text {probe }}>$ $\tau$. The $2 / R$ Coulomb curve models the final $\operatorname{Ar}^{2+}\left(3 p^{-2}\right)-\operatorname{Ar}^{+}\left(3 p^{-1}\right)$ state. Having reached this curve, the particle is propagated to asymptotically large internuclear distances $(R=100 \AA)$ and the KER is determined [cf. Eq. (9)]. In order to match the full experiment, a constant background of events generated by directly populating the $2 / R$ Coulomb curve at $R_{\mathrm{eq}}$ is included in the simulation.

As already discussed in Sec. III $B$, the $R$-dependent IR-ionization probability in the probe step can be eliminated by selecting events within a certain KER window. Therefore, to simplify our simulation, a constant IR-ionization probability is assumed.

The result of the simulation for a common input lifetime of $\tau_{\text {sim }}=400$ fs is shown in Fig. 4(e). The KER of the $\mathrm{Ar}^{2+}+\mathrm{Ar}^{+}$ channel is plotted vs the pump-probe delay. The agreement with the experiment is convincing. For the projection onto the delay axis [cf. Fig. 4(f)], the same KER window of 7.0-8.4 eV is used for the experiment and simulation, and an exponential fit returns the input lifetime $\tau_{\text {sim. }}$. This shows that the delay-dependent yield of Coulombexploded $\mathrm{Ar}^{2+}$ ions for a fixed KER window allows determining the CT lifetime.

\section{Extraction of the charge-transfer lifetime}

Figure 5 shows the yields of $\mathrm{Ar}^{2+}$ and $\mathrm{Ar}^{+}$ions for KER windows of 7.0-8.4 eV and 4.8-5.8 eV, respectively. As already mentioned, the IR probe will only ionize the $\operatorname{Ar}^{+}\left(3 p^{-2} n l\right)$ $-\operatorname{Ar}^{+}\left(3 p^{-1}\right)$ states to two-site triply ionized states, if the charge transfer has already occurred [cf. Eq. (8)]. This explains the sharp increase/decrease in the count rate and the subsequent slow decay/rise, which gives the CT lifetime.

As shown in the work of Mizuno et al. ${ }^{20}$ the lifetime $\tau_{i}$ of the initial $\mathrm{Ar}^{2+}\left(3 s^{-1} 3 p^{-1}\right)-\mathrm{Ar}$ state is imprinted in the falling edge of the

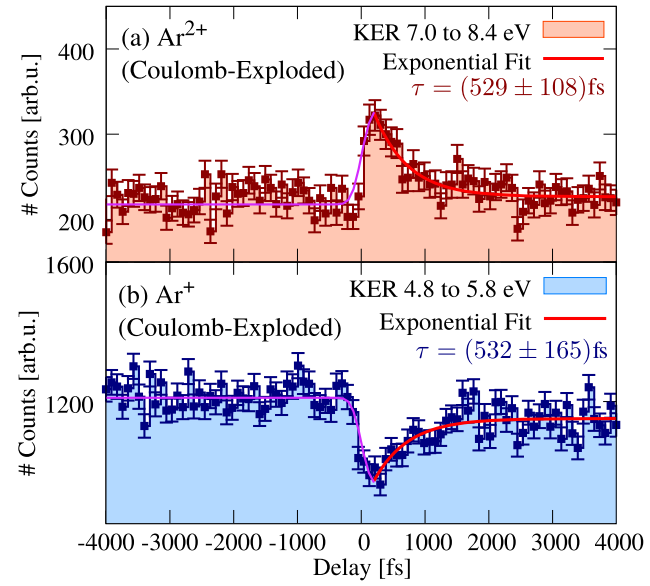

FIG. 5. (a) Yield of $\mathrm{Ar}^{2+}$ ions after the Coulomb explosion of triply charged $\mathrm{Ar}$ dimers within the KER window 7.0-8.4 eV as a function of pump-probe delay. (b) Yield of $\mathrm{Ar}^{+}$ions within the KER window 4.8-5.8 eV as a function of pump-probe delay. The red lines are exponential fits to the data. The magenta lines depict the error function whose FWHM of 280 fs marks the upper limit of the temporal resolution of the experiment (cf. Sec. II A).

yield distribution, if $\tau_{i}$ is large compared to the dissociation time $\tau_{\text {diss }}$ of the $\operatorname{Ar}^{+}\left(3 p^{-2} n l\right)-\operatorname{Ar}^{+}\left(3 p^{-1}\right)$ states. In the present case, the dissociation time is defined by the time a wave packets needs to propagate from the respective crossing to the maximum allowed internuclear distance $\left[R\left(t_{d}\right) \approx 7.5 \AA\right]$ to obtain total $\mathrm{Ar}^{2+}+\mathrm{Ar}^{+}$KERs within the window 7.0-8.4 eV. Within our classical model, the dissociation time of the $\operatorname{Ar}^{+}\left(3 p^{-2} n l\right)-\operatorname{Ar}^{+}\left(3 p^{-1}\right)$ states is estimated to be $\tau_{\text {diss }}$ $=(115 \pm 5)$ fs.

As shown in Fig. 5, two exponential fits result in lifetimes of $\tau_{\mathrm{Ar}^{2+}}=(529 \pm 108)$ fs and $\tau_{\mathrm{Ar}^{+}}=(532 \pm 165)$ fs, respectively, which yield a mean value of $\tau_{\exp }=(531 \pm 136)$ fs. In the present case, this is the mean lifetime of all charge transfers happening at the crossings as $\tau_{i}>\tau_{\text {diss }}$.

\section{E. Calculation of the charge-transfer lifetime}

In our calculations, the total lifetime of the charge-transfer process is estimated from the ratio of the vibrational period $\tau_{\text {vibr }}$ of the $\operatorname{Ar}^{2+}\left(3 s^{-1} 3 p^{-1}\right)-\operatorname{Ar}^{1} \Sigma_{g}^{+}$state and the total probability $P_{\mathrm{CT}}$ for charge transfer from this state to all $\operatorname{Ar}^{+}\left(3 p^{-2} n l\right)-\operatorname{Ar}^{+}\left(3 p^{-1}\right)$ states crossing it. In its turn, the total probability can be estimated as $P_{\mathrm{CT}}=1-P_{i}$, where $P_{i}$ is the probability that the wave packet stays on the $\operatorname{Ar}^{2+}\left(3 s^{-1} 3 p^{-1}\right)-\operatorname{Ar}^{1} \Sigma_{g}^{+}$state within a single vibrational period. Assuming independent charge transfer processes between the different crossings, $P_{i}$ is then equal to the product of squared Landau-Zener probabilities $P_{i \rightarrow f_{k}}$ corresponding to each transition from $\operatorname{Ar}^{2+}\left(3 s^{-1} 3 p^{-1}\right)-\operatorname{Ar}$ to $\operatorname{Ar}^{+}\left(3 p^{-2} n l\right)-\operatorname{Ar}^{+}\left(3 p^{-1}\right)$,

$$
P_{i}=\prod_{k} P_{i \rightarrow f_{k}}^{2} .
$$

Here, $i$ and $f_{k}$ are the adiabatic states, which asymptotically correspond to the $\operatorname{Ar}^{2+}\left(3 s^{-1} 3 p^{-1}\right)-\operatorname{Ar}$ and the $\operatorname{Ar}^{+}\left(3 p^{-2} n l\right)-\operatorname{Ar}^{+}\left(3 p^{-1}\right)$ states crossing it. Each of these probabilities was computed using the Landau-Zener formula, 


$$
P_{i \rightarrow f_{k}}=\exp \left(-\frac{2 \pi}{\hbar} \frac{\left|\Delta E_{i f_{k}}\right|^{2}}{\mathrm{~d} \Delta E / \mathrm{d} t}\right),
$$

where $\Delta E_{i f_{k}}$ is the energy splitting between the two states at the avoided crossing, and $\mathrm{d} \Delta E / \mathrm{d} t=v\left(\mathrm{~d} E_{i} / \mathrm{d} r-\mathrm{d} E_{f_{k}} / \mathrm{d} r\right)$, where $v$ and $\mathrm{d} E_{i / f_{k}} / \mathrm{d} r$ are the classical velocity and derivatives taken at the crossing point. ${ }^{42-44}$ Finally, for the total lifetime of the charge transfer process from the $\operatorname{Ar}^{2+}\left(3 s^{-1} 3 p^{-1}\right)-\operatorname{Ar}^{1} \Sigma_{g}^{+}$state, we obtain $\tau_{\mathrm{LZ}}=559 \mathrm{fs}$.

\section{CONCLUSIONS}

In conclusion, we studied relaxation processes following sequential XUV photoabsorption in the argon dimer. The different relaxation channels were disentangled by measuring the kinetic energy release of $\mathrm{Ar}^{+}$and $\mathrm{Ar}^{2+}$ ions. Moreover, we identified ultrafast interatomic charge transfer via avoided crossings in an energy regime, where interatomic Coulombic decay is energetically forbidden. By means of a time-resolved XUV-pump IR-probe experiment, it is shown that the $\operatorname{Ar}^{2+}\left(3 s^{-1} 3 p^{-1}\right)-\mathrm{Ar}$ states mainly decay to dissociative $\operatorname{Ar}^{+}\left(3 p^{-2} n l\right)-\operatorname{Ar}^{+}\left(3 p^{-1}\right)$ states by charge transfer within $\tau_{\exp }=(531 \pm 136)$ fs. The measured lifetime is in good agreement with the theoretical value of $\tau_{\mathrm{LZ}}=559 \mathrm{fs}$ determined using Landau-Zener probabilities. Our experiment shows that the charge-transfer process is the predominant decay mechanism of these high-energy doubly-ionized states of the dimer and underlines the importance of nonlocal relaxation processes in weakly bound systems.

\section{ACKNOWLEDGMENTS}

We thank the entire FLASH team including accelerator, photon diagnostics, and beamline staff. K.S. was funded by a Peter Paul Ewald Fellowship from the Volkswagen Foundation. A.I.K. acknowledges the financial support of DFG through the QUTIF Priority Programme. L.S.C. gratefully acknowledges the funding from ERC (AdG No. 692657). We are grateful to C. Kaiser and B. Knape from the MPIK, Heidelberg, who helped us in setting up the experiment.

\section{REFERENCES}

${ }^{1}$ L. S. Cederbaum, J. Zobeley, and F. Tarantelli, Phys. Rev. Lett. 79, 4778 (1997).

${ }^{2}$ T. Jahnke, J. Phys. B: At., Mol. Opt. Phys. 48, 082001 (2015).

${ }^{3}$ T. Jahnke, A. Czasch, M. S. Schöffler, S. Schössler, A. Knapp, M. Käsz, J. Titze, C. Wimmer, K. Kreidi, R. E. Grisenti, A. Staudte, O. Jagutzki, U. Hergenhahn, H. Schmidt-Böcking, and R. Dörner, Phys. Rev. Lett. 93, 163401 (2004).

${ }^{4}$ K. Schnorr, A. Senftleben, M. Kurka, A. Rudenko, L. Foucar, G. Schmid, A. Broska, T. Pfeifer, K. Meyer, D. Anielski, R. Boll, D. Rolles, M. Kübel, M. F. Kling, Y. H. Jiang, S. Mondal, T. Tachibana, K. Ueda, T. Marchenko, M. Simon, G. Brenner, R. Treusch, S. Scheit, V. Averbukh, J. Ullrich, C. D. Schröter, and R. Moshammer, Phys. Rev. Lett. 111, 093402 (2013).

${ }^{5}$ R. Santra, J. Zobeley, L. S. Cederbaum, and N. Moiseyev, Phys. Rev. Lett. 85, 4490 (2000).

${ }^{6}$ S. Marburger, O. Kugeler, U. Hergenhahn, and T. Möller, Phys. Rev. Lett. 90, 203401 (2003)

${ }^{7}$ V. Averbukh and L. S. Cederbaum, Phys. Rev. Lett. 96, 053401 (2006).

${ }^{8}$ M. Mucke, M. Braune, S. Barth, M. Förstel, T. Lischke, V. Ulrich, T. Arion, U. Becker, A. Bradshaw, and U. Hergenhahn, Nat. Phys. 6, 143 (2010).

${ }^{9}$ T. Jahnke, H. Sann, T. Havermeier, K. Kreidi, C. Stuck, M. Meckel, M. Schöffler, N. Neumann, R. Wallauer, S. Voss, A. Czasch, O. Jagutzki,
A. Malakzadeh, F. Afaneh, T. Weber, H. Schmidt-Böcking, and R. Dörner, Nat. Phys. 6, 139(2010).

${ }^{10}$ G. Öhrwall, N. Ottosson, W. Pokapanich, S. Legendre, S. Svensson, and O. Björneholm, J. Phys. Chem. B 114, 17057 (2010).

${ }^{11}$ Y. Morishita, X.-J. Liu, N. Saito, T. Lischke, M. Kato, G. Prümper, M. Oura, H. Yamaoka, Y. Tamenori, I. H. Suzuki, and K. Ueda, Phys. Rev. Lett. 96, 243402 (2006).

${ }^{12}$ K. Ueda, X.-J. Liu, G. Prümper, H. Fukuzawa, Y. Morishita, and N. Saito, J. Electron Spectrosc. Relat. Phenom. 155, 113 (2007).

${ }^{13}$ P. Lablanquie, T. Aoto, Y. Hikosaka, Y. Morioka, F. Penent, and K. Ito, J. Chem. Phys. 127, 154323 (2007).

${ }^{14}$ M. Kimura, H. Fukuzawa, K. Sakai, S. Mondal, E. Kukk, Y. Kono, S. Nagaoka, Y. Tamenori, N. Saito, and K. Ueda, Phys. Rev. A 87, 043414 (2013).

${ }^{15}$ M. Kimura, H. Fukuzawa, T. Tachibana, Y. Ito, S. Mondal, M. Okunishi, M. Schöffler, J. Williams, Y. Jiang, Y. Tamenori, N. Saito, and K. Ueda, J. Phys. Chem. Lett. 4, 1838 (2013).

${ }^{16}$ X. Ren, E. J. Al Maalouf, A. Dorn, and S. Denifl, Nat. Commun. 7, 11093 (2016).

${ }^{17}$ J. Rist, T. Miteva, B. Gaire, H. Sann, F. Trinter, M. Keiling, N. Gehrken, A. Moradmand, B. Berry, M. Zohrabi, M. Kunitski, I. Ben-Itzhak, A. Belkacem, T. Weber, A. L. Landers, M. Schöffler, J. B. Williams, P. Kolorenc, K. Gokhberg, T. Jahnke, and R. Dörner, Chem. Phys. 482, 185 (2017).

${ }^{18}$ S. D. Stoychev, A. I. Kuleff, F. Tarantelli, and L. S. Cederbaum, J. Chem. Phys. 128, 014307 (2008)

${ }^{19}$ T. Miteva, Y.-C. Chiang, P. Kolorenč, A. I. Kuleff, K. Gokhberg, and L. S. Cederbaum, J. Chem. Phys. 141, 064307 (2014).

${ }^{20}$ T. Mizuno, P. Cörlin, T. Miteva, K. Gokhberg, A. I. Kuleff, L. S. Cederbaum, T. Pfeifer, A. Fischer, and R. Moshammer, J. Chem. Phys. 146, 104305 (2017).

${ }^{21}$ J. Zobeley, R. Santra, and L. S. Cederbaum, J. Chem. Phys. 115, 5076 (2001).

${ }^{22}$ K. Sakai, S. Stoychev, T. Ouchi, I. Higuchi, M. Schöffler, T. Mazza, H. Fukuzawa, K. Nagaya, M. Yao, Y. Tamenori, A. I. Kuleff, N. Saito, and K. Ueda, Phys. Rev. Lett. 106, 033401 (2011).

${ }^{23}$ R. Johnsen and M. A. Biondi, Phys. Rev. A 18, 996 (1978).

${ }^{24}$ N. Saito, Y. Morishita, I. H. Suzuki, S. D. Stoychev, A. I. Kuleff, L. S. Cederbaum, X.-J. Liu, H. Fukuzawa, G. Prümper, and K. Ueda, Chem. Phys. Lett. 441, 16 (2007).

${ }^{25}$ A. Devaquet, Pure Appl. Chem. 41, 455 (1975).

${ }^{26}$ X.-J. Liu, N. Saito, H. Fukuzawa, Y. Morishita, S. Stoychev, A. Kuleff, I. H. Suzuki, Y. Tamenori, R. Richter, G. Prümper, and K. Ueda, J. Phys. B: At., Mol. Opt. Phys. 40, F1 (2007).

${ }^{27}$ W. Ackermann, G. Asova, V. Ayvazyan, A. Azima, N. Baboi et al., Nat. Photonics 1, 336 (2007).

${ }^{28}$ K. Tiedtke, A. Azima, N. von Bargen, L. Bittner, S. Bonfigt, S. Düsterer, B. Faatz, U. Frühling, M. Gensch, C. Gerth, N. Guerassimova, U. Hahn, T. Hans, M. Hesse, K. Honkavaar, U. Jastrow, P. Juranic, S. Kapitzki, B. Keitel, T. Kracht, M. Kuhlmann, W. Li, M. Martins, T. Nunez, E. Plönjes, H. Redlin, E. Saldin, E. Schneidmiller, J. Schneider, S. Schreiber, N. Stojanovic, F. Tavella, S. Toleikis, R. Treusch, H. Weigelt, M. Wellhöfer, H. Wabnitz, M. Yurkov, and J. Feldhaus, New J. Phys. 11, 023029 (2009).

${ }^{29}$ H. Redlin, A. Al-Shemmary, A. Azima, N. Stojanovic, F. Tavella, I. Will, and S. Düsterer, Nucl. Instrum. Methods Phys. Res., Sect. A 635, S88 (2011).

${ }^{30}$ J. Ullrich, R. Moshammer, A. Dorn, R. Dörner, L. Schmidt, and H. SchmidtBöcking, Rep. Prog. Phys. 66, 1463 (2003).

${ }^{31}$ J. Schirmer and A. Barth, Z. Phys. A 317, 267 (1984).

${ }^{32}$ Y. Velkov, T. Miteva, N. Sisourat, and J. Schirmer, J. Chem. Phys. 135, 154113 (2011).

${ }^{33}$ D. E. Woon and T. H. Dunning, Jr., J. Chem. Phys. 98, 1358 (1993).

${ }^{34}$ The additional s, $p$, and d diffuse functions were generated as an even tempered sequence from the most diffuse $\mathrm{s}, \mathrm{p}$, and $\mathrm{d}$ basis functions with exponents $\xi=\alpha \beta^{l}$, where $\alpha$ is the exponent of the previous function, $\beta=10$, and $l=-0.5$.

${ }^{35}$ M. W. Schmidt, K. K. Baldridge, J. A. Boatz, S. T. Elbert, M. S. Gordon, J. H. Jensen, S. Koseki, N. Matsunaga, K. A. Nguyen, S. Su, T. L. Windus, M. Dupuis, and J. A. Montgomery, J. Comput. Chem. 14, 1347 (1993). 
${ }^{36}$ A. Kramida, Y. Ralchenko, J. Reader, and NIST ASD Team, NIST Atomic Spectra Database (version 5.4) (Online), available: http://physics.nist.gov/asd, National Institute of Standards and Technology, Gaithersburg, MD, 2017.

${ }^{37}$ P. R. Herman, P. E. LaRocque, and B. P. Stoicheff, J. Chem. Phys. 89, 4535 (1988).

${ }^{38}$ B. Manschwetus, H. Rottke, G. Steinmeyer, L. Foucar, A. Czasch, H. SchmidtBöcking, and W. Sandner, Phys. Rev. A 82, 013413 (2010).

${ }^{39}$ B. Ulrich, A. Vredenborg, A. Malakzadeh, M. Meckel, K. Cole, M. Smolarski, Z. Chang, T. Jahnke, and R. Dörner, Phys. Rev. A 82, 013412 (2010).

${ }^{40} \mathrm{~J}$. Wu, A. Vredenborg, B. Ulrich, L. P. H. Schmidt, M. Meckel, S. Voss, H. Sann, H. Kim, T. Jahnke, and R. Dörner, Phys. Rev. Lett. 107, 043003 (2011).
${ }^{41}$ K. Schnorr, A. Senftleben, G. Schmid, S. Augustin, M. Kurka, A. Rudenko, L. Foucar, A. Broska, K. Meyer, D. Anielski, R. Boll, D. Rolles, M. Kübel, M. F. Kling, Y. H. Jiang, S. Mondal, T. Tachibana, K. Ueda, T. Marchenko, M. Simon, G. Brenner, R. Treusch, S. Scheit, V. Averbukh, J. Ullrich, T. Pfeifer, C. D. Schröter, and R. Moshammer, J. Electron Spectrosc. Relat. Phenom. 204, 245 (2015).

${ }^{42}$ L. Landau, Phys. Z. Sowjetunion 2, 46 (1932).

${ }^{43}$ C. Zener, Proc. R. Soc. A 137, 696 (1932).

${ }^{44}$ E. Stueckelberg, "Theorie der unelastischen Stösse zwischen Atomen," in An Unconventional Figure of Twentieth Century Physics, edited by G. Wanders, J. Lacki, and H. Ruegg (Birkhäuser, Basel, 2009). 